\title{
Influence of Silica Based Waste Materials on the Mechanical And Physical Properties of Mortar
}

\author{
${ }^{1}$ S.I. Balang , ${ }^{1}$ N. Mohamed Sutan, ${ }^{1}$ I. Yakub, ${ }^{2}$ M.S. Jaafar and ${ }^{3}$ K.A. Matori \\ ${ }^{1}$ Faculty of Engineering, Universiti Malaysia Sarawak, 94300 Kota Samarahan, Sarawak, \\ ${ }^{2}$ Faculty of Engineering, Universiti Putra Malaysia, 43400 Serdang, Selangor, \\ ${ }^{3}$ Faculty of Science,Universiti Putra Malaysia, 43400 Serdang, Selangor, \\ MALAYSIA \\ Date Received: $4^{\text {th }}$ March 2015 \\ Date Published: $30^{\text {th }}$ April 2015
}

\begin{abstract}
This is an investigation on the influence of silica based waste materials namely silica fume (SF) and recycled vase (RV) on the physical and mechanical properties of mortar. Results showed that 15\%SF modified mortar achieved the highest strength and lowest water absorption capability compared to Control mortar and other mixtures. The result was confirmed by water absorption capability test for the same mixtures where $15 \% \mathrm{SF}$ modified mortar was found to absorb the least. Furthermore, combination of $15 \% \mathrm{SF}$ and $10 \% \mathrm{RV}$ achieved the lowest water absorption compared to other combinations samples but higher than Control and 15\% SF modified mortar. The results of this study indicated that SF is highly pozzolanic material that can be an excellent cement replacement material to produce highperformance concrete. Study on pozzolanc behavior of SF samples subjected to longer hydration time is needed. Further microstructural investigation is needed to confirm the hypothesis on retardation of hydration due to unreactive RV.
\end{abstract}

Keywords: Silica Fume, Recycle Vase, Mortar, Compressive Strength, Water Absorption

\section{INTRODUCTION}

$\mathrm{T}$ HE increased in the utilization of waste materials in construction product came from greater awareness of current and potential uses of alternative and recycled materials and wider realization of the environmental benefits accrued. The practice of partially replacing cement in concrete and mortar with waste and other less energy intensive processed materials will contribute environmental protection and sustainable construction in the future.

To be qualified as a candidate for cement replacement for concrete or mortar, the waste material must be silica based and very fine. The specific chemical property is the classification of a material to be pozzolanic. Pozzolan is defined as a siliceous material which, in itself, possesses little or no cementing property but which will, in finely divided form and in the presence of moisture, react chemically with calcium hydroxide at ordinary temperatures to form compounds possessing cementitious properties that can improve concrete and mortar properties [1].

Silica Fume (SF), a byproduct or waste from silicon metal or ferrosilicon alloys production, is a very reactive pozzolan due to its chemical and physical properties which are high in silica and fine particle size, therefore it can be used as partial cement replacement for concrete and mortar production [2-6].

One possible source of pozzolanic waste material is calcined clay [7-9]. Waste calcined clay used in this study, which is derived from recycled vase (RV) in the form of vase powder. Therefore, this study is designed to investigate the combination of waste calcined clay and silica fume as partial cement replacement or only silica fume as partial cement replacement on the improvement of durability properties of concrete modified mortar. The purpose of this research is to investigate the pozzolanic activity of binary binder system of by-product silica fume (SF) as partial cement replacement, and ternary binder of SF and waste calcined clay (RV). The objective of this research is to investigate the mechanical and physical properties of $\mathrm{SF}, \mathrm{RV}$ modified mortar and their combination on namely their compressive strength and water absorption capability. These properties can be used as an indirect indication of extent of hydration and pozzolanic reactivity of modified mortar.

S.I Balang is with the Department of Civil Engineering, Faculty of Engineering, Universiti Malaysia Sarawak, 94300 Kota Samarahan, Sarawak,Malaysia N. Mohamed Sutan is with the Department of Civil Engineering, Faculty of Engineering, Universiti Malaysia Sarawak, 94300 Kota Samarahan, Sarawak, Malaysia (corresponding author, phone: 082-58 3232; e-mail: msnorsuzailina@ feng.unimas.my).

I. Yakub is with the Department of Chemical Engineering and Energy Sustainability, Faculty of Engineering, Universiti Malaysia Sarawak, 94300 Kota Samarahan, Sarawak,Malaysia (e-mail: yibrahim@feng.unimas.my ).

M. S. Jaafar is with the Department of Civil Engineering, Faculty of Engineering, Universiti Putra Malaysia, 43400 Serdang, Selangor,Malaysia. (e-mail: msj@upm.my ).

K. A. Matori is with the Department of Physics, Faculty of Science, Universiti Putra Malaysia, 43400 Serdang, Selangor,Malaysia. (e-mail: khamirul@upm.edu.my ). 


\section{MATERIALS AND METHODS}

\subsection{Materials}

Silica based materials chosen as cement replacement were Silica Fume (SF) according to ASTM C 1240 obtained from Grace Construction and Recycle Vase (RV) or waste vase collected from Naga Emas Ceramic Ind. Sdn. Bhd. The waste vase was cleansed with water to remove dirt and washable contaminants. It was then crushed into smaller pieces and finely grounded to particle size finer than $75 \mu \mathrm{m}$. Table 1 shows the chemical composition of OPC and RV obtained from X-ray fluorescence (XRF) analysis. Cement used was Ordinary Portland Cement (OPC) (ASTM Type 1 recognized by ASTM C150) manufactured by Cahaya Mata Sarawak Cement Sdn. Bhd. (CMS). The physical properties and chemical compositions of the OPC and RV are shown in Table 1 . SF contains up to $97 \% \mathrm{SiO}_{2}$. Water and fine aggregate used in this study were regular tap water and natural river sand, respectively. Glenium was used as superplasticizer (SP).

Table 1. Physical properties and chemical composition of OPC and RV

\begin{tabular}{|c|c|c|c|}
\hline & \multicolumn{3}{|c|}{$\begin{array}{c}\text { Ordinary Portland Cement (OPC) } \\
\text { ASTM Type } 1\end{array}$} \\
\hline \multirow{5}{*}{ Physical Properties } & Bulk density & \multicolumn{2}{|c|}{$1.2-1.4 \mathrm{~kg} / \mathrm{L}$} \\
\hline & Specific gravity & \multicolumn{2}{|r|}{3.15} \\
\hline & Amount retained on 90 um sieve (\%) & \multicolumn{2}{|r|}{$2 \%$} \\
\hline & Amount retained on $45 \mathrm{um}$ sieve $(\%)$ & \multicolumn{2}{|r|}{$18 \%$} \\
\hline & & OPC & Recycle Vase (RV) \\
\hline \multirow{14}{*}{$\begin{array}{l}\text { Chemical } \\
\text { Composition } \\
\qquad(\%)\end{array}$} & Silicon dioxide, $\mathrm{SiO}_{2}$ & 19.34 & 53.30 \\
\hline & Aluminum oxide, $\mathrm{Al}_{2} \mathrm{O}_{3}$ & 5.20 & 18.36 \\
\hline & Ferric oxide, $\mathrm{Fe}_{2} \mathrm{O}_{3}$ & 3.41 & 16.43 \\
\hline & Sulphur trioxide, $\mathrm{SO}_{3}$ & 2.85 & 0.73 \\
\hline & Magnesium oxide, $\mathrm{MgO}$ & 1.44 & - \\
\hline & Potassium oxide, $\mathrm{K}_{2} \mathrm{O}$ & 0.47 & 5.54 \\
\hline & Calcium oxide, $\mathrm{CaO}$ & 64.75 & 2.12 \\
\hline & Titanium Dioxide, $\mathrm{TiO}_{2}$ & - & 1.92 \\
\hline & Barium oxide, $\mathrm{BaO}$ & - & 0.61 \\
\hline & Sodium oxide, $\mathrm{Na}_{2} \mathrm{O}$ & 0.10 & - \\
\hline & Manganese oxide, $\mathrm{MnO}$ & - & 0.26 \\
\hline & Loss on ignition, LOI & 3.42 & 0.24 \\
\hline & Free Cao & 1.39 & 0.17 \\
\hline & Total Alkali & 0.41 & 0.41 \\
\hline
\end{tabular}

\subsection{Sample preparation for Compressive Strength (CS) and Water Absorption tests.}

The mix proportion for mortar was set at 0.6 binder to sand ratio (b/s) and 0.5 water to binder ratio (w/b) for all specimens that were casted into $150 \mathrm{~mm}$ cubes for compressive strength (CS) and water absorption tests. Cement was replaced by SF (10\%, 15\% and 20\%) by weight as binary binder and combination of SF (15\%, 20\%) and RV (10\%, $20 \%$ and $30 \%$ ) by weight as ternary binder. All samples were prepared using the mix proportion as shown in Table 2 and were wet cured in the concrete laboratory at Universiti Malaysia Sarawak for 3, 7, 14, 21, and 28 days. All mixes except Control has an SP dosage of 1 litre per 100kg of binders.

Table 2. Mix proportions for all specimens

\begin{tabular}{cccccc}
\hline Sample & $\begin{array}{c}\mathrm{SF} \\
\left(\mathrm{kg} / \mathrm{m}^{3}\right)\end{array}$ & $\begin{array}{c}\text { RV Powder } \\
\left(\mathrm{kg} / \mathrm{m}^{3}\right)\end{array}$ & $\begin{array}{c}\text { OPC } \\
\left(\mathrm{kg} / \mathrm{m}^{3}\right)\end{array}$ & $\begin{array}{c}\text { Sand } \\
\left(\mathrm{kg} / \mathrm{m}^{3}\right)\end{array}$ & $\begin{array}{c}\text { Water } \\
\left(\mathrm{kg} / \mathrm{m}^{3}\right)\end{array}$ \\
\hline Control & - & - & 683.36 & 1138.86 & 341.66 \\
\hline $\mathrm{SF}=10 \%$ & 68.34 & - & 615.02 & 1138.86 & 344.51 \\
\hline $\mathrm{SF}=15 \%$ & 136.67 & - & 547.00 & 1138.86 & 342.62 \\
\hline $\mathrm{SF}=20 \%$ & 205.00 & - & 478.36 & 1138.86 & 344.51 \\
\hline $15 \% \mathrm{SF}$, 10\% RV & 136.67 & 68.34 & 478.66 & 1138.86 & 343.51 \\
\hline 15\% SF, 20\% RV & 136.67 & 136.67 & 342.00 & 1138.86 & 343.51 \\
\hline 15\% SF, 30\% RV & 136.67 & 205.00 & 205.00 & 1138.86 & 343.51 \\
\hline 20\% SF, 10\% RV & 205.00 & 68.34 & 410.02 & 1138.86 & 343.51 \\
\hline
\end{tabular}


UNIMAS e-Journal of Civil Engineering

\begin{tabular}{lccccc}
\hline $20 \% \mathrm{SF}, 20 \% \mathrm{RV}$ & 205.00 & 136.67 & 273.63 & 1138.86 & 343.51 \\
\hline $20 \% \mathrm{SF}, 30 \% \mathrm{RV}$ & 205.00 & 342.00 & 136.63 & 1138.86 & 343.51 \\
\hline
\end{tabular}

\subsection{Compressive Strength (CS) and Water Absorption tests.}

CS and water absorption tests were performed on day 3, 7, 14, 21, and 28 according to BS 1881-116 (1983) [10] and BS 1881 Part-5 (1983) Part 122, respectively [11]. CS test was used to determine the maximum compressive load that a sample can carry per unit area. Meanwhile water absorption test was used to evaluate water absorption capability of a sample. Both tests give the overall picture of the quality of mortar as it hydrates. Each strength and water absorption values were the average of value of three specimens. Compressive strength for each sample was calculated by using Equation (1)[10]. Meanwhile, water absorption capability for each sample was determined by using Equation 2[11].

$$
\text { Compressive strength }=\underline{\text { Failure loading } \times 1000(\mathrm{~N})}
$$

Water Absorption $(\%)=(\mathrm{B}-\mathrm{A}) / \mathrm{A} \times 100 \%$

where, $A=$ weight of dry cube and $B=$ weight of wet cube

\section{RESULTS AND DISCUSSION}

\subsection{Compressive Strength (CS) test}

Figure 1 and 2 show the compressive strength of SF and SFVC samples compared to Control samples. The increasing compressive strength as cement hydration proceeded from day 3 to 28 in both figures is an expected and established trend [12]. Figure 1 shows $15 \%$ SF sample has the highest 28 day comprehensive strength compared to other samples. This is caused by pozzolanic reaction of silica in SF with Calcium Hydroxide $(\mathrm{CH})$ from cement hydration that produced more Calcium Silicate Hydrate (C-S-H) that refines the pores and densifies the cement matrix[1-9][12].

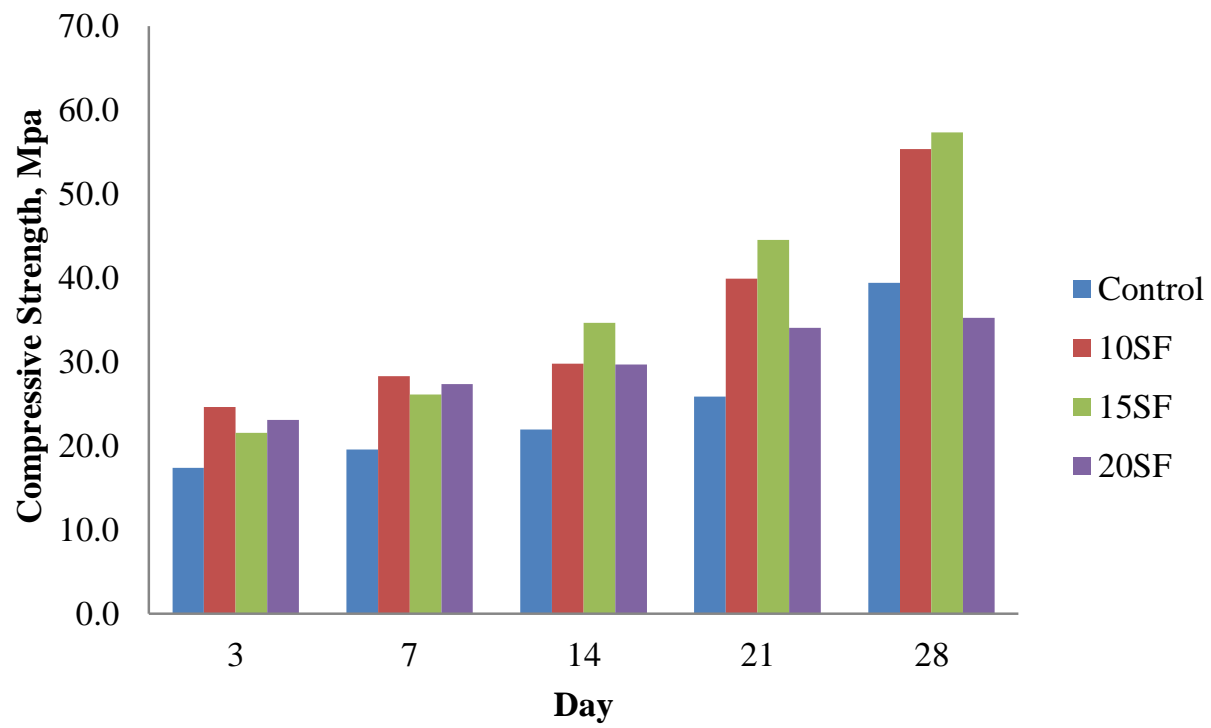

Figure 1. Comparison of Compressive Strength between Control and SF modified mortars

Figure 2 shows that the combination of $15 \% \mathrm{SF}$ and $10 \% \mathrm{RV}$ produced higher strength than other combinations of SF and $\mathrm{RV}$ but there was no significant reduction in the compressive strength of these mixtures when compared to the control mortar and 15\% SF sample. RV may not have reactive silica that can produce pozzolanic behaviour. Besides, the presence of 
RV may retard the reactivity of SF and cement hydration. Further microstructural investigation need to be done to confirm this hypothesis.

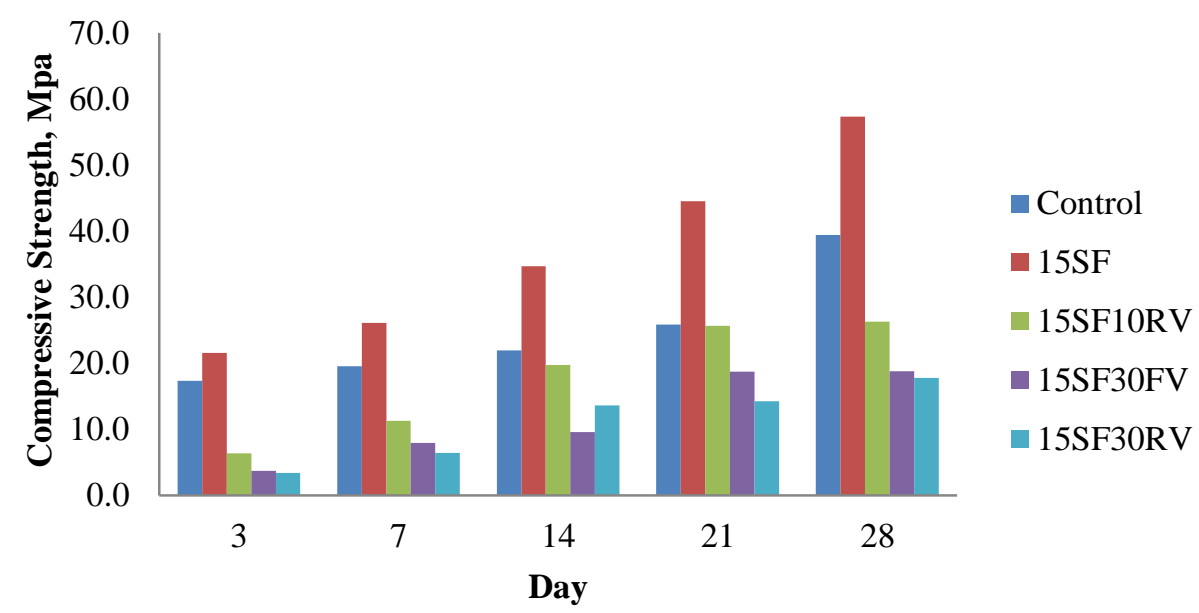

Figure 2. Comparison of Compressive Strength between Control, SF and SFRV modified mortars

\subsection{Water Absorption test}

Figure 3 and 4 show the water absorption of SF and SFVC compared to Control samples. From Figure 3,15\% SF sample has the lowest water absorption at day 28 which indicated that there are less interconnected capillary voids in the sample [4][5].Figure 4 shows that the combination of $15 \% \mathrm{SF}$ and $10 \% \mathrm{RV}$ achieved the lowest water absorption compared to the other combinations samples. However, the absorption is still higher than $15 \% \mathrm{SF}$ and Control. This is an indication that the unreactive RV may retard hydration [8][9]. The water absorption trend for all samples is the opposites of compressive strength trend and this fact has already been an established trend [12].

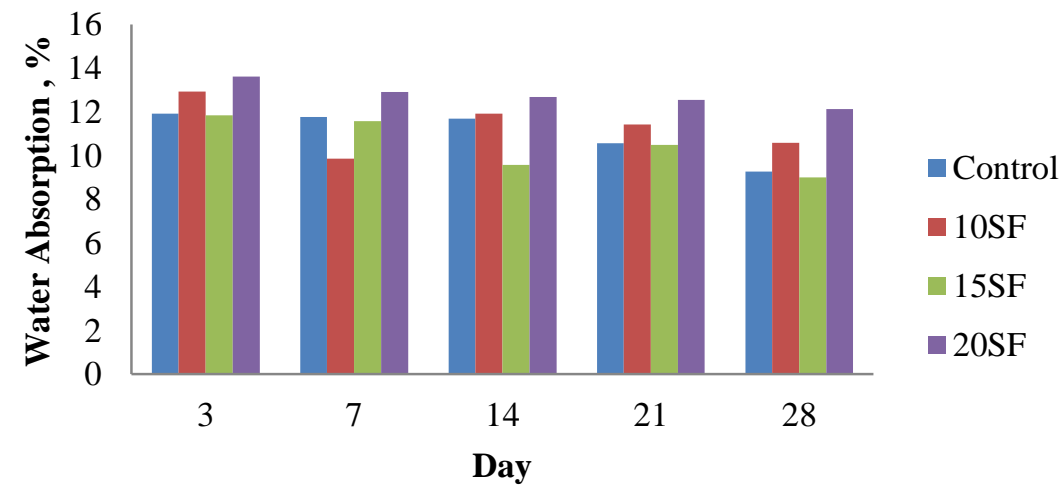

Figure 3. Comparison of 24-hr water absorption capability between Control and SF modified mortars 


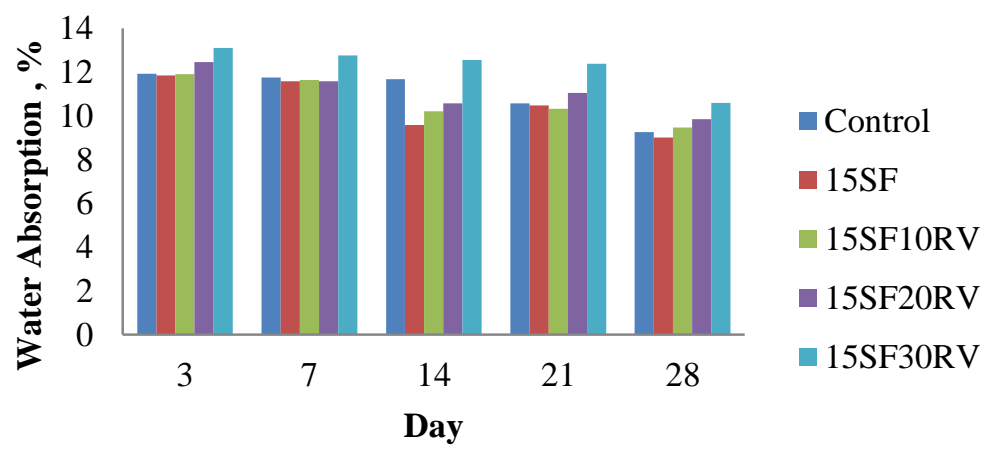

Figure 4. Comparison of 24-hr water absorption capability between Control, SF and SFRV mortar

\section{CONCLUSIONS}

The results of this study confirmed that SF is highly pozzolanic material that can be an excellent cement replacement material to produce high-performance concrete. In terms of compressive strength, $15 \%$ SF modified mortar achieved the highest strength and lowest water absorption capability compared to Control mortar and other mixtures. The result was confirmed by water absorption capability results for the same mixtures where 15\% SF modified mortar absorbed the least. Furthermore, combination of $15 \% \mathrm{SF}$ and $10 \% \mathrm{RV}$ achieved the lowest water absorption compared to other combinations samples but higher than Control and 15\% SF modified mortar. The results of this study indicated that SF is highly pozzolanic material that can be an excellent cement replacement material to produce high-performance concrete. Study on pozzolanc behavior of SF samples subjected to longer hydration time is needed. Further microstructural investigation is needed to confirm the hypothesis on retardation of hydration due to unreactive RV.

\section{Acknowledgment}

The authors wish to acknowledge Ministry of Education and Universiti Malaysia Sarawak for supporting this work under ERGS/TK04(02)/1011/2013 (08) and RACE/c(1)/1108/2013(16) grants.

\section{REFERENCES}

[1] P. K. Mehta, “Natural Pozzolans: Supplementary Cementing Materials in Concrete,” CANMET Special Publication 86, pp.1-33,1987

[2] M.J. Shannag, "High strength concrete containing natural pozzolan and silica fume," Cement and Concrete Research, vol 22,no. 6, pp. 399-406, Dec.2000 doi:10.1016/S0958-9465(00)00037-8

[3] Houssam A. Toutanji, “The influence of silica fume on the compressive strength of cement paste and mortar," Cement and Concrete Research, vol 25,no. 7, pp. 1591-1602, Oct.1995 doi:10.1016/0008-8846(95)00152-3

[4] G.Appa Rao, "Investigations on the performance of silica fume-incorporated cement pastes and mortars," Cement and Concrete Research, vol 33,no. 11, pp. 1765-1770, Nov.2003 doi:10.1016/S0008-8846(03)00171-6

[5] S. Bhanja, B. Sengupta, "Influence of silica fume on the tensile strength of concrete," Cement and Concrete Research, vol 35, no. 4, pp. 743-747, Apr.2005 doi:10.1016/j.cemconres.2004.05.024

[6] J. Zelić, D. Rušić, D. Ve za \& R. Krstulović, "The role of silica fume in the kinetics and mechanisms during the early stage of cement hydration," Cement and Concrete Research, vol 30,no. 9, pp. 1655-1662, Oct.2000 doi:10.1016/S0008-8846(00)00374-4

[7] B.B. Sabir, S. Wild \& J. Bai, "Metakaolin and calcined clays as pozzolans for concrete : a review," Cement and Concrete Research, vol 23,no. 6, pp. 441-454, Dec.2001 doi:10.1016/S0958-9465(00)00092-5

[8] K. Scrivener, J. F. Martirena \& M. Antoni, "Tackling social housing through the commercial use low clinker cementitious systems: Innovation on the use of calcined clay as Supplementary Cementitious material," in Conference Proceedings 2012 nternational Conference of Tackling Technologies for sustainable development: A way to reduce poverty? pp.1-15

[9] R. D. Toledo Filho, J.P. Gonçalves, B.B. Americano, E.M.R. Fairbairna, "Potential for use of crushed waste calcined-clay brick as a supplementary cementitious material in Brazil," Cement and Concrete Research, vol 37,no. 9, pp.1357-1365, Sept.2007. doi:10.1016/j.cemconres.2007.06.005

[10] BS 1881-116(1983) Testing concrete Method for determination of compressive strength of concrete cubes

[11] BS 1881 Part-5 (1983) Part 122. Method for determination of water absorption.

[12] A.M. Neville, Properties of Concrete England: Pearson Education Limited (2002) 